\section{Lamellar cells in Pacinian and Meissner corpuscles are touch sensors}

\author{
Yury A. Nikolaev ${ }^{1}$, Viktor V. Feketa ${ }^{1,2,3}$, Evan O. Anderson ${ }^{1 *}$, Eve R. Schneider ${ }^{1 \dagger}$, \\ Elena O. Gracheva ${ }^{1,2,3 \ddagger}$, Sviatoslav N. Bagriantsev ${ }^{1 \neq}$
}

\begin{abstract}
The skin covering the human palm and other specialized tactile organs contains a high density of mechanosensory corpuscles tuned to detect transient pressure and vibration. These corpuscles comprise a sensory afferent neuron surrounded by lamellar cells. The neuronal afferent is thought to be the mechanical sensor, whereas the function of lamellar cells is unknown. We show that lamellar cells within Meissner and Pacinian corpuscles detect tactile stimuli. We develop a preparation of bill skin from tactile-specialist ducks that permits electrophysiological recordings from lamellar cells and demonstrate that they contain mechanically gated ion channels. We show that lamellar cells from Meissner corpuscles generate mechanically evoked action potentials using R-type voltage-gated calcium channels. These findings provide the first evidence for R-type channel-dependent action potentials in non-neuronal cells and demonstrate that lamellar cells actively detect touch. We propose that Meissner and Pacinian corpuscles use neuronal and non-neuronal mechanoreception to detect mechanical signals.
\end{abstract}

Copyright $\odot 2020$

The Authors, some rights reserved; exclusive licensee American Association for the Advancement of Science. No claim to original U.S. Government Works. Distributed under a Creative Commons Attribution NonCommercial License 4.0 (CC BY-NC).

\section{INTRODUCTION}

The sense of touch is essential for a range of physiological processes, including detection of pain and pleasure, object recognition, foraging, and environment navigation. It facilitates the establishment of maternal bonds and underlies the development of social behaviors (1). The human palm contains a dense population of mechanosensory end-organs, including Pacinian, Meissner, and Ruffini corpuscles, along with Merkel cell-neurite complexes. The same or analogous structures are present in the skin of most vertebrates (2). Mechanosensory end-organs are thus essential for precise manipulation of tools and objects, and performing fine tactile tasks (3-5). Animals that are mechanosensory specialists have organs that are functionally analogous to the human palm, including the star organ of the star-nosed mole and the bill of tactile-foraging waterfowl. These organs contain hundreds of mechanosensory corpuscles per square millimeter of skin, allowing mechanosensory specialists to rely on touch during their search for food $(2,6-8)$.

The two most numerous types of mechanosensory corpuscles in the human palm are Pacinian and Meissner corpuscles. Pacinian corpuscles detect high-frequency vibration, whereas Meissner are tuned to lower frequencies $(2,5,9)$. Both types are innervated by myelinated mechanoreceptors that arise from somatosensory ganglia. Neuronal mechanoreceptors are thought to be the only touch sensors within corpuscles and produce rapidly adapting firing patterns when their mechanically gated ion channels are activated by touch $(4,10,11)$. In Pacinian corpuscles, the mechanoreceptor is surrounded by onion-like sheaths formed by lamellar cells, whereas

\footnotetext{
'Department of Cellular and Molecular Physiology, Yale University School of Medicine, New Haven, CT 06520, USA. ${ }^{2}$ Department of Neuroscience, Yale University School of Medicine, New Haven, CT 06520, USA. ${ }^{3}$ Program in Cellular Neuroscience, Neurodegeneration and Repair, Yale University School of Medicine, New Haven, CT 06520, USA

*Present address: TetraScience Inc., Boston, MA 02108, USA.

†Present address: Department of Biology, University of Kentucky, Lexington, KY 40506, USA.

‡Corresponding author.Email: elena.gracheva@yale.edu (E.O.G.); slav.bagriantsev@ yale.edu (S.N.B.)
}

it is sandwiched between two or more lamellar cells in Meissner corpuscles. The functional role of lamellar cells is obscure, but they are thought to provide structural support for the neuronal afferent, facilitate small-amplitude vibrations (12), and serve as a passive mechanical filter for static stimuli (13). There are reports that some lamellar cells are immunoreactive for synaptic proteins, suggesting an active, rather than passive, role in touch sensing (14-16). However, despite their widespread presence in vertebrates, no functional studies of lamellar cells from Meissner- or Pacinian-like corpuscles from any species exist, and their physiological roles remain unknown (15).

\section{RESULTS}

To test whether lamellar cells play an active role in the detection of touch, we developed a glabrous skin preparation from the bill of Pekin duck, a tactile-specialist bird $(2,17)$. Duck bill skin contains a dense population of Pacinian- and Meissner-like corpuscles, referred to as Herbst and Grandry corpuscles, respectively $(18,19)$. Like their mammalian counterparts, duck corpuscles are innervated by rapidly adapting myelinated mechanoreceptors and are tuned to detect transient pressure and vibration (19-22). Optical and electron microscopic analyses of an ex vivo preparation of duck bill skin (Fig. 1A and Materials and Methods) revealed a mixed population of Pacinian and Meissner corpuscles, which could be distinguished by their unique morphology and size (Fig. 1, B and C). Duck Pacinian corpuscles had an oval structure, $\sim 35$ to $120 \mu \mathrm{m}$ in size $(n=140$ corpuscles), and comprised a mechanoreceptive neuronal afferent surrounded by an inner core and outer capsule formed by lamellar cells (Fig. 1, D to F). Duck Meissner corpuscles were more spherical and smaller in size ( $\sim 15$ to $35 \mu \mathrm{m}$ in diameter, $n=50$ corpuscles) than Pacinian corpuscles and consisted of a neuronal mechanoreceptor surrounded by two or more lamellar cells (Fig. 1, G to I) $(14,18)$. Although the number of outer core layers in duck Pacinian corpuscles and the number of lamellar cells in duck Meissner corpuscles are lower than the number of analogous structures in humans, the overall architecture of duck corpuscles is similar to their human 


\section{A}
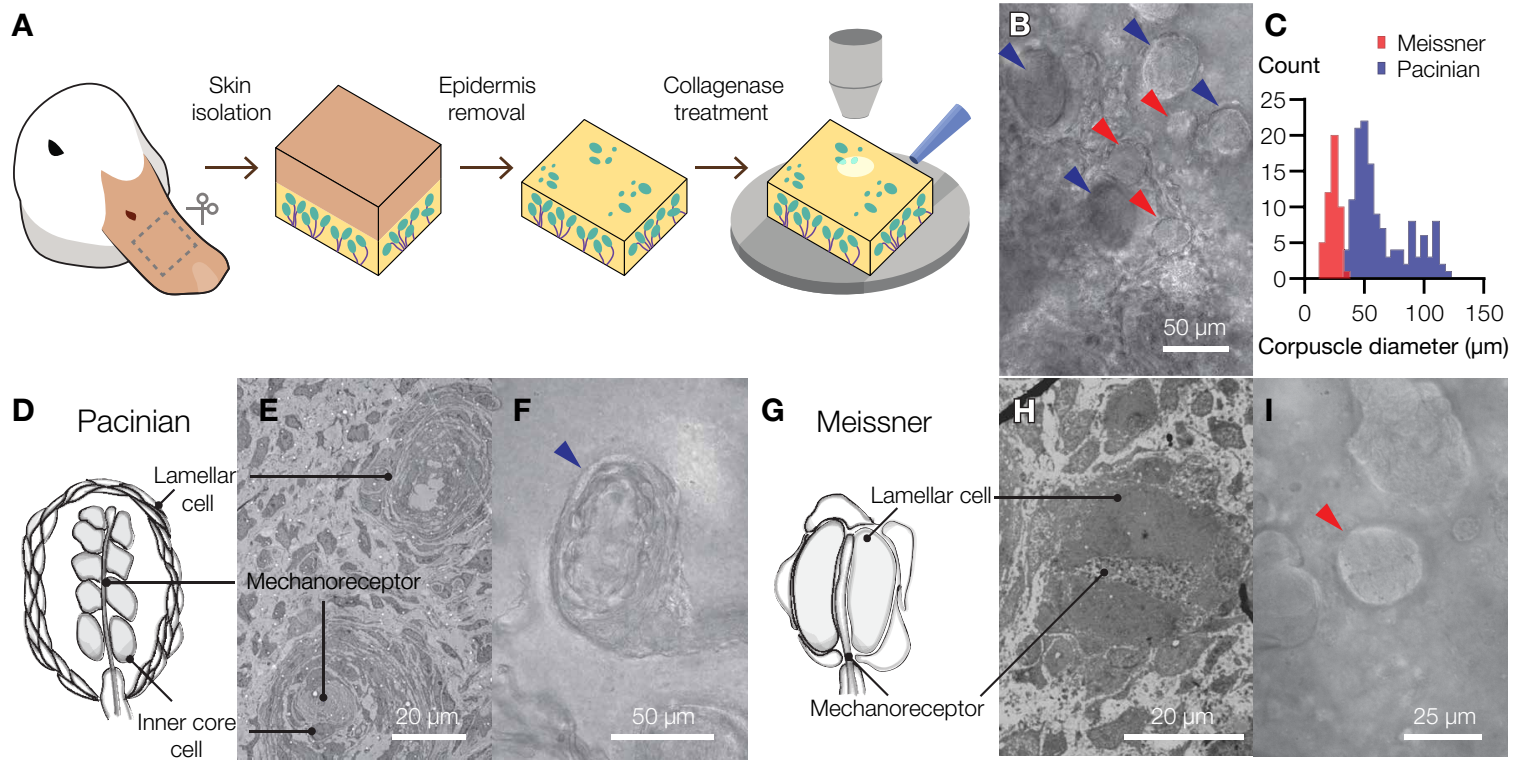

Fig. 1. The bill skin of a tactile-specialist duck has Pacinian and Meissner corpuscles. (A) Schematic illustration of the preparation of duck bill skin for electrophysiological and optical analysis of mechanosensory corpuscles. (B) A bright-field microscopic image of a mixed population of Pacinian corpuscles (blue arrowheads) and Meissner corpuscles (red arrowheads) in a patch of duck skin from the dorsal surface of the upper bill. (C) Size distribution of visible Meissner and Pacinian corpuscles in duck bill skin (50 Meissner and 140 Pacinian corpuscles in total). (D to I) Illustrations ( $D$ and $G$ ), electron microscopy images ( $E$ and $H$ ), and close-up bright-field microscopy images ( $\mathrm{F}$ and $\mathrm{I}$ ) of mechanosensory corpuscles. Pacinian corpuscles are composed of outer core lamellar cells surrounding an inner bulb of inner core cells and a neuronal mechanoreceptor. In Meissner corpuscles, the mechanoreceptor is sandwiched between two or more lamellar cells.

counterparts. In addition, our electron microscopy images showed that lamellar cells from duck Meissner corpuscles contain dense core vesicles (fig. S1), similar to the structures reported in Meissner lamellar cells from humans $(14,23)$. The presence of Pacinian and Meissner corpuscles in duck bill skin suggests that it as a good model system for the human palm. In contrast, mouse glabrous skin normally lacks Pacinian corpuscles, which are located in the periosteal membrane (24).

Having identified lamellar cells in mechanosensory corpuscles from duck bill skin, we sought to characterize them in situ by injecting the fluorescent dye Lucifer yellow using a patch electrode (Fig. 2, A and B). The dye remained confined within the volume of each cell for 15 min after injection, suggesting that a diffusion barrier existed between lamellar cells in both corpuscular types. The long, flat outer lamellar cells in Pacinian corpuscles had an average length of $11.42 \pm 0.72 \mu \mathrm{m}$ (means \pm SEM, $n=7$ cells; Fig. $2 \mathrm{~A}$ ). The hemispherical lamellar cells in Meissner corpuscles had an average diameter of $17.56 \pm 1.65 \mu \mathrm{m}$ ( $n=7$ cells; Fig. $2 \mathrm{~B})$. Electrophysiological recordings revealed that Pacinian and Meissner lamellar cells had a whole-cell membrane capacitance of $9.6 \pm 1.4$ and $24.6 \pm 4.6$ pF, respectively (Fig. 2C). In addition, Pacinian lamellar cells had a resting membrane potential of $-51.9 \pm 2.0 \mathrm{mV}$ and a high apparent input resistance of $5.8 \pm 1.8 \mathrm{G} \Omega$, whereas Meissner lamellar cells had a significantly more negative resting potential of $-73.5 \pm 2.4 \mathrm{mV}$ and lower input resistance of $1.5 \pm 0.4 \mathrm{G} \Omega$ (Fig. 2C).

We next asked whether lamellar cells are mechanosensitive in situ. Stimulation of either Pacinian or Meissner lamellar cells with a glass probe produced robust mechanically activated (MA) currents, which increased in amplitude as probe displacement increased (Fig. 2, D and E, and fig. S2A). Although MA currents from Pacinian lamellar cells had a significantly slower rise time than Meissner cell currents $\left(\tau_{\text {rise }}=2.8 \pm 0.3\right.$ and $1.4 \pm 0.2 \mathrm{~ms}$ for Pacinian and Meissner cells, respectively, $P=0.005)$, both values were within the range of MA currents recorded from mechanosensitive neurons (Fig. 2F) $(25,26)$. Following activation, Pacinian lamellar MA currents decayed $\left(\tau_{\text {decay }}=48.7 \pm 7.0 \mathrm{~ms}\right)$, reaching 20 to $68 \%$ of their peak amplitude by the end of the 150-ms stimulus (Fig. 2D and fig. S2, $\mathrm{B}$ and C). In some cells, up to $30 \%$ fraction of peak MA current persisted after retraction of the probe and, in each case, returned to baseline within $10 \mathrm{~s}$ (fig. S2, B and D). The inactivation rate of Pacinian lamellar MA current was in the range of slowly inactivating neuronal mechanoreceptors (Fig. 2G). In contrast, Meissner lamellar MA currents decayed significantly faster $\left(\tau_{\text {decay }}=11.8 \pm 2.3 \mathrm{~ms}, P<0.0001\right.$ versus Pacinian lamellar MA current), similar to mechanoreceptors with fast and intermediate inactivation kinetics (27-31), and lacked a persistent, noninactivating component (Fig. 2, D and G). Both types of MA current had a linear voltage dependence and a near-zero reversal potential (Fig. 2, H and I), characteristic of a nonselective cation conductance. However, they differed in their voltage dependence of inactivation: depolarization slightly decreased $\tau_{\text {decay }}$ in Pacinian lamellar cells $(P=0.111)$ and increased $\tau_{\text {decay }}$ in Meissner cells $(P=0.019$; Fig. $2 \mathrm{~J})$.

Together, these data reveal that lamellar cells of Pacinian and Meissner corpuscles are intrinsically mechanosensitive. The fast activation kinetics of lamellar MA currents, linear voltage dependence, and lack of ion selectivity are consistent with the ion channelbased mechanotransduction mechanism in somatosensory neurons $(28,32-35)$. The significant differences in the rate and voltage dependence of MA current decay between Pacinian and Meissner lamellar cells from duck bill skin indicate that they each express different mechanically gated ion channels or the same channels with modified function. 
A

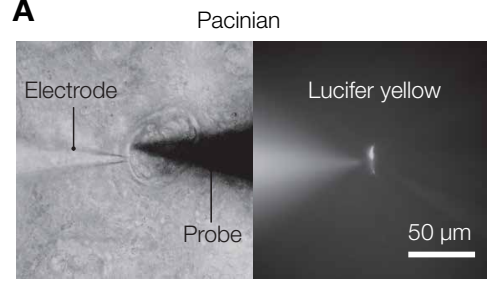

B

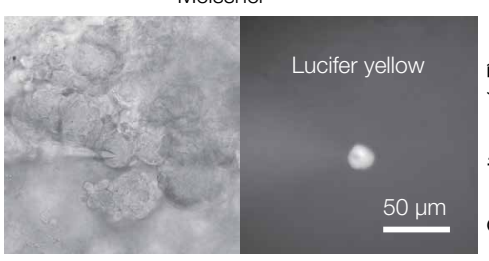

C

$P=0.017 \quad P<0.0001 \quad P=0.025$
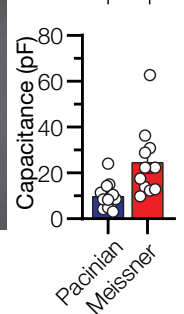

$\mathbf{F}$

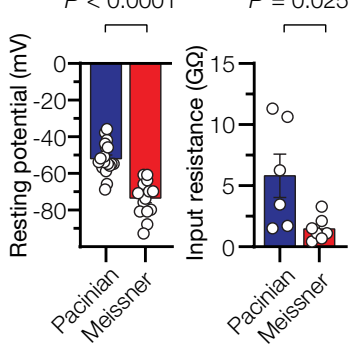

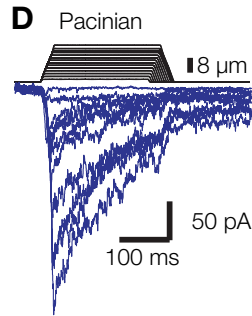

H

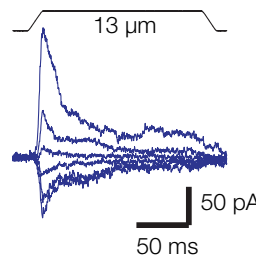

Meissner
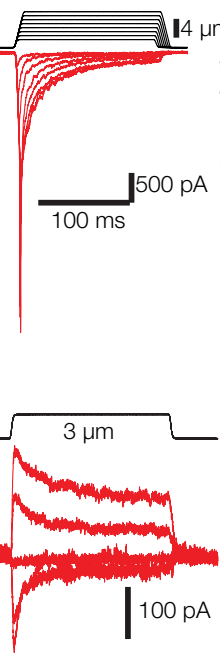

E
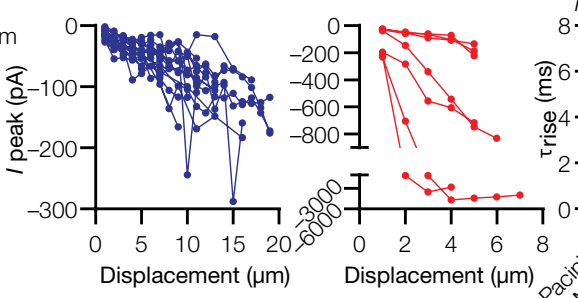

$P=0.005$

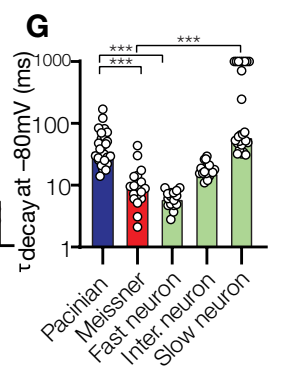

I

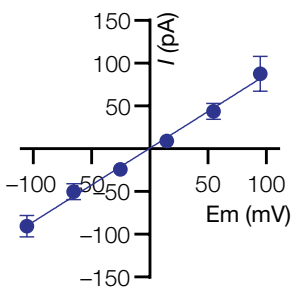

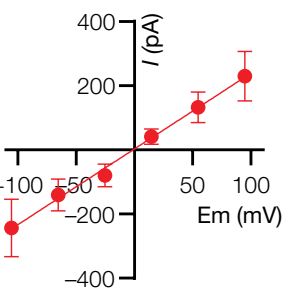

J

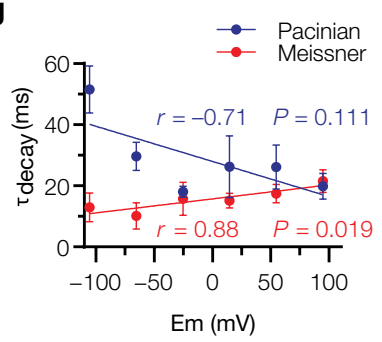

Fig. 2. Lamellar cells of Pacinian and Meissner corpuscles are mechanosensitive. (A and B) Representative bright-field (left) and fluorescent images (right) of lamellar cells from Pacinian and Meissner corpuscles filled with Lucifer yellow via the recording electrode. A glass probe is positioned nearby to deliver mechanical stimulation. (C) Electrophysiological characteristics of lamellar cells. Significance was calculated using unpaired two-tailed $t$ test. Open circles denote individual cells. (D) Representative MA currents elicited from lamellar cells by mechanical indentation using a glass probe. (E) Quantification of peak MA current amplitude in Pacinian (left, $n=19$ cells) and Meissner (right, $n=7$ cells) lamellar cells in response to indentation with a glass probe. Lines connect measurements from individual cells. (F) Quantification of MA current rise time $\left(\tau_{\text {rise }}\right)$ recorded in lamellar cells and in duck trigeminal mechanoreceptors with fast, intermediate, and slow MA current. The difference between means is significant; $F_{4,61}=3.49, P=0.013$, one-way analysis of variance (ANOVA) with Tukey's post hoc multiple comparisons test. Open circles denote individual cells. (G) Quantification of MA current inactivation rate $\left(\tau_{\text {decay }}\right)$ recorded in lamellar cell and duck trigeminal mechanoreceptors. $\tau_{\text {decay }}$ values greater than $1000 \mathrm{~ms}$ are plotted as 1000 . Bars represent median. Open circles denote individual cells. The difference between medians is significant; $P<0.0001$, Kruskal-Wallis test. ${ }^{* * *} P<0.0001$, Dunn's post hoc multiple comparisons test. (H) Representative MA currents elicited from lamellar cells in response to indentation at different voltages. (I) Voltage dependence of peak MA current from eight Pacinian and five Meissner lamellar cells, fitted to the linear equation. (J) Quantification of MA current $\tau_{\text {decay }}$ from seven Pacinian and seven Meissner lamellar cells, fitted to the linear equation. $r$, Pearson's correlation coefficient; $P$ denotes the probability of the line slope being equal to 0 . Data are presented as means $\pm S E M$ from at least three independent skin preparations.

Given the similarities between lamellar cells and neuronal mechanoreceptors, we wanted to find out whether lamellar cells are excitable. We first asked whether they have voltage-activated conductances by depolarizing and hyperpolarizing their membranes to different test potentials. Such voltage stimulation of Pacinian lamellar cells failed to reveal voltage-activated potassium, sodium, or calcium currents (fig. S3, A and B). Moreover, depolarizing current injection failed to evoke any action potentials and instead induced a linear depolarization of the membrane with a slope averaging $2.7 \mathrm{mV} / \mathrm{pA}$, typical of nonexcitable cells (fig. S3C). In contrast, lamellar cells from Meissner corpuscles displayed robust voltage-gated potassium currents (Fig. 3A). When these currents were blocked by replacing $\mathrm{K}^{+}$with $\mathrm{Cs}^{+}$in the patch electrode, we identified voltage-gated inward currents that were largely blocked by $\mathrm{Cd}^{2+}$ or depletion of extracellular $\mathrm{Ca}^{2+}$, suggesting that they were mediated by voltagegated calcium $\left(\mathrm{Ca}_{\mathrm{v}}\right)$ channels (Fig. 3, B to F). Ratiometric live-cell calcium imaging of duck bill skin revealed that high extracellular potassium-induced depolarization evoked an increase in intracellular calcium in lamellar cells of Meissner, but not Pacinian, corpuscles (Fig. 3, G to I), corroborating our finding that Meissner lamellar cells express $\mathrm{Ca}_{\mathrm{v}}$ channels.

Having established that Meissner lamellar cells express voltagegated ion channels, we asked whether they could fire action potentials. Depolarizing current injection triggered repetitive action potential firing in Meissner lamellar cells with a rheobase averaging $16.07 \pm 1.9 \mathrm{pA}$ (Fig. $4 \mathrm{~A}$ and fig. S4A). The voltage-current relationship was strongly rectifying, characteristic of excitable cells (fig. S4B). In agreement with our finding that Meissner lamellar cells express $\mathrm{Ca}_{\mathrm{v}}$ channels, the depletion of extracellular $\mathrm{Ca}^{2+}$ or addition of $\mathrm{Cd}^{2+}$ dampened firing (Fig. 4, A, B, and E), whereas tetrodotoxin, a blocker of voltage-gated sodium channels $\left(\mathrm{Na}_{\mathrm{v}}\right)$, did not (Fig. 4, $\mathrm{C}$ and $\mathrm{E})$. Transcriptomic analysis revealed that several types of $\mathrm{Ca}_{\mathrm{v}}$ 
A

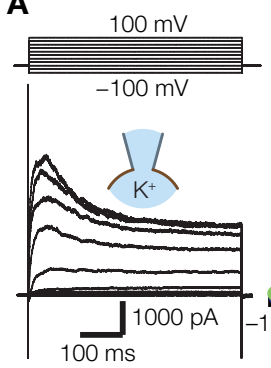

D

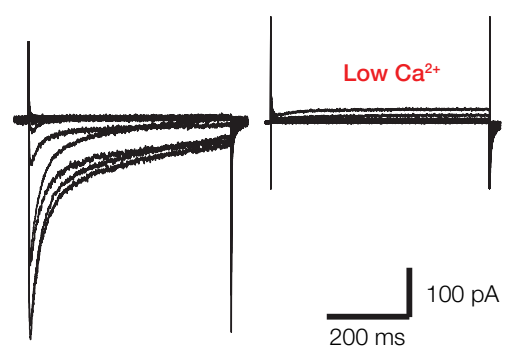

B

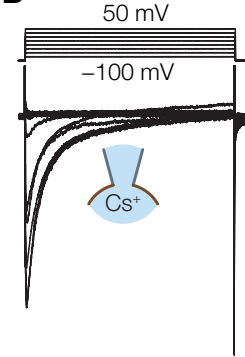

E

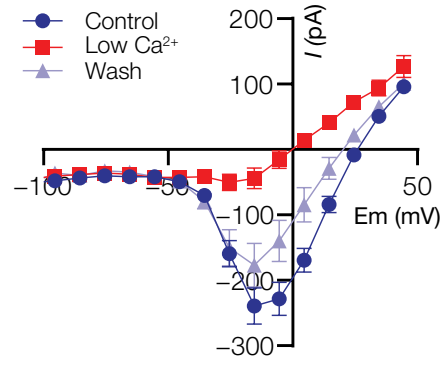

C

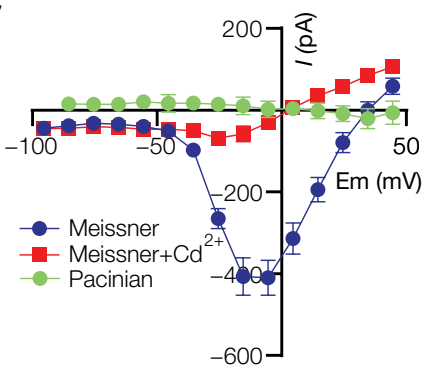

F

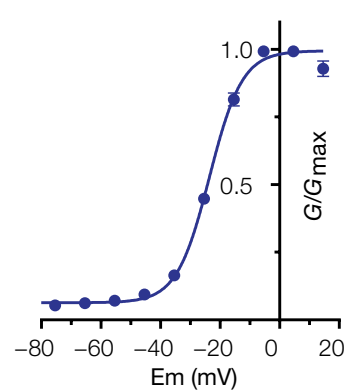

$\mathrm{Em}(\mathrm{mV})$
G
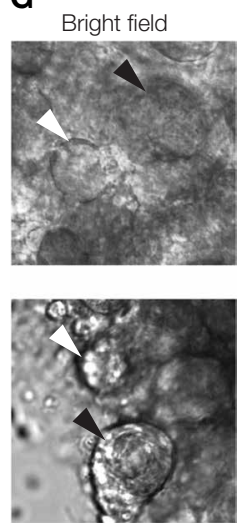
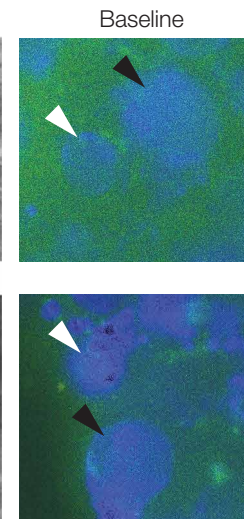
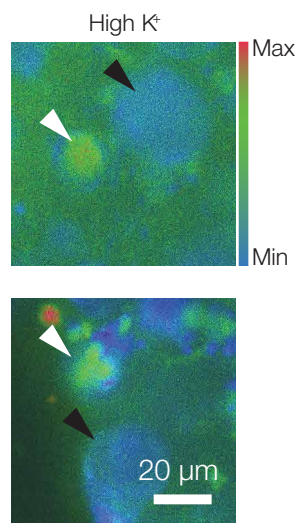

H High $\mathrm{K}^{+}$

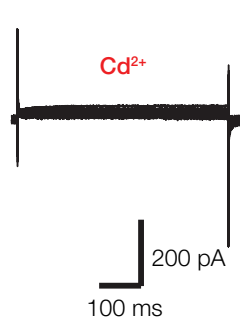

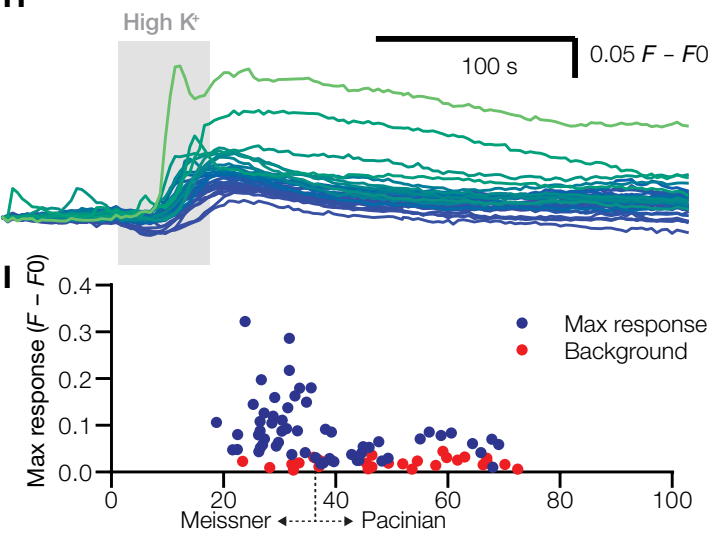

Corpuscle diameter $(\mu \mathrm{m})$

Fig. 3. Lamellar cells from Meissner corpuscles express voltage-activated channels. (A) Current traces and current-voltage (IM) plots of voltage-activated $\mathrm{K}^{+}$currents (means $\pm \mathrm{SEM}, n=12$ Meissner and 5 Pacinian lamellar cells). (B to E) Current traces and $I V$ plots of voltage-activated $\mathrm{Ca}^{2+}$ currents in the presence of a general Ca $\mathrm{V}_{\mathrm{V}}$ channel blocker $300 \mu \mathrm{M} \mathrm{Cd}^{2+}\left[(\mathrm{B})\right.$ and $(\mathrm{C}), n=5$ cells] and upon depletion of extracellular $\mathrm{Ca}^{2+}$ to $20 \mu \mathrm{M}$, low $\mathrm{Ca}^{2+}[(\mathrm{D})$ and $(\mathrm{E}), n=7$ Meissner and $n=7$ Pacinian lamellar cells]. Data are means \pm SEM. (F) Conductance-voltage relationship of $C a_{v}$ current, fitted to the Boltzmann equation, with half-maximal activation voltage $\left(V_{1 / 2}\right)$ of $-23.5 \pm 0.4 \mathrm{mV}$ (means $\pm \mathrm{SEM}, n=12$ Meissner lamellar cells). (G) Representative partial fields of view of live-cell ratiometric Fura-2 AM calcium imaging of Meissner (white arrowheads) and Pacinian (black arrowheads) corpuscles in duck bill skin. Application of $135 \mathrm{mM}$ extracellular potassium (high $\mathrm{K}^{+}$) elevates intracellular calcium in lamellar cells of Meissner but not in Pacinian corpuscles or in the neuronal ending within the corpuscles $(\mathbf{H})$ Example traces from Meissner corpuscles in response to application of high $\mathrm{K}^{+}$. Colors of the traces correspond to the color scale bar in (G) based on peak response value. (I) Quantification of peak calcium signal in Pacinian and Meissner corpuscles and in skin areas of comparable sizes devoid of corpuscles (background) in response to high $\mathrm{K}^{+}$. Dots represent individual data points. All data are from at least three independent skin preparations.

channel alpha subunits were expressed in duck bill skin (Fig. 4F). However, pharmacological blockade of L-, N-, T-, and P/Q-type $\mathrm{Ca}_{\mathrm{v}}$ channels failed to affect firing (Fig. 4E and fig. S5, A to E, G, and H), suggesting that although these channels could be expressed in Meissner lamellar cells, their activity is not critical for action potential generation. In contrast, SNX-482, a specific blocker of R-type $\left(\mathrm{Ca}_{\mathrm{v}} 2.3\right)$ channels, completely abolished action potential firing (Fig. 4, D and E, and fig. S5F). Thus, action potential firing in Meissner lamellar cells must be predominantly mediated by R-type $\mathrm{Ca}_{\mathrm{v}}$ channels.

Because the rheobase for Meissner lamellar cell firing was comparable to the amplitude of MA current produced by direct mechani- cal stimulation, we wondered whether mechanical stimulation alone could elicit firing. Indentation with a glass probe triggered repetitive firing in Meissner lamellar cells with a threshold of $4.6 \pm 0.4 \mu \mathrm{m}$ ( $n=7$ cells; Fig. $4 \mathrm{G}$ and fig. S4C); the number of action potentials increased in proportion to the degree of indentation (Fig. 4G). Notably, the number of action potentials during mechanical stimulation exponentially decayed with a time constant $\tau_{\text {decay }}=16.6 \mathrm{~ms}$, similar to the average $\tau_{\text {decay }}$ for MA current in these cells $(11.8 \mathrm{~ms})$, further supporting the causative relationship between these events (Fig. 4H). Together, these data demonstrate robust mechanically evoked excitability in Meissner lamellar cells. 
A

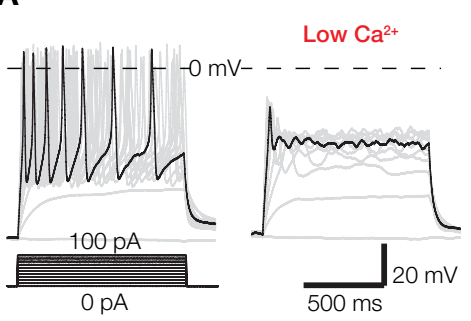

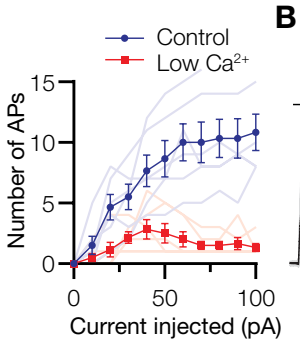

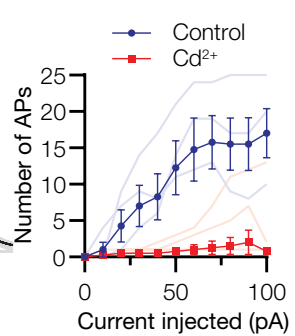

C
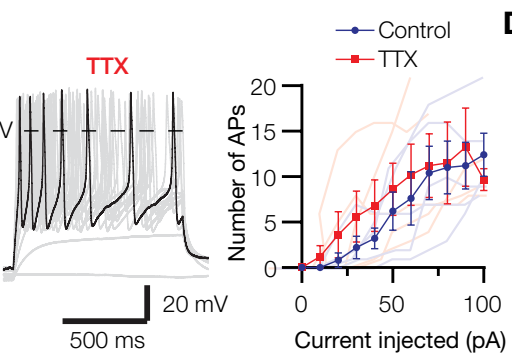

D
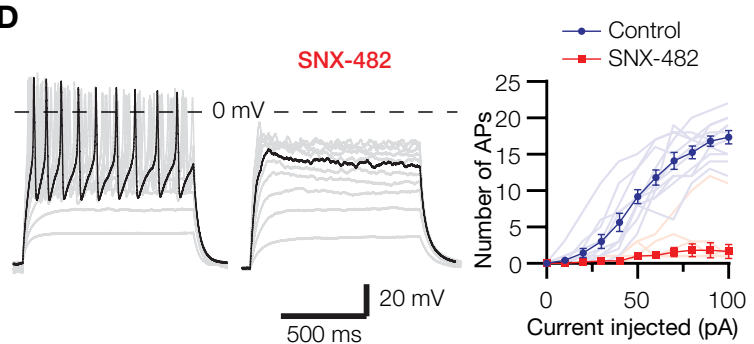

E

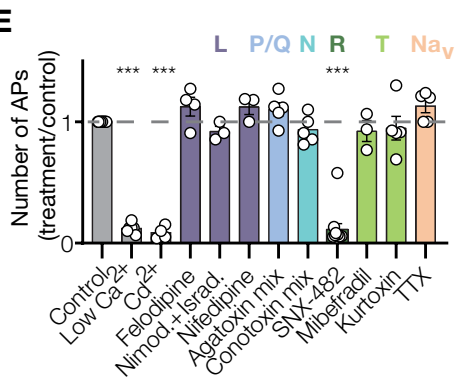

F

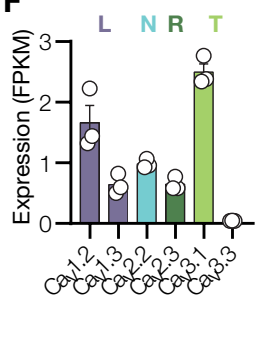

G

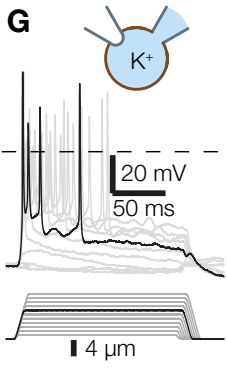

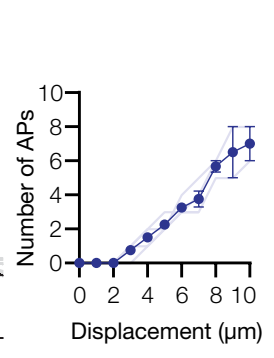

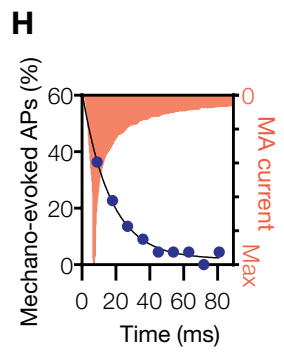

Fig. 4. Lamellar cells from Meissner corpuscles are excitable mechanosensors. (A to D) Exemplar action potentials (APs; left and middle) and spike quantification (right) obtained by current injection into Meissner lamellar cells in the presence of low ( $20 \mu \mathrm{M})$ extracellular $\mathrm{Ca}^{2+}[(\mathrm{A}), n=6$ cells $]$, pan-Ca blocker $\mathrm{Cd}^{2+}[(\mathrm{B}), n=4$ cells], $\mathrm{Na}$ blocker tetrodotoxin (TTX; (C), $n=5$ cells], R-type Cav2.3 blocker SNX-482 [(D), $n=11$ cells]. Thin lines in quantification panels represent individual cells; thick lines connect means \pm SEM. (E) Pharmacological profile of Meissner lamellar cell firing upon injection of a 100-pA current. Letters indicate Ca $a_{v}$ type. Open circles represent individual cells. The effect of treatment is significant. $F_{11,53}=75.57, P<0.0001$, one-way ANOVA; ***P 0.0001 versus control, Dunnett's test. (F) Quantification of $C a_{v}$ alpha subunit expression in duck bill skin ( $n=3$ animals). FPKM, number of mRNA fragments per kilobase of exon per million fragments mapped. (G) Mechanical stimulation evokes action potential firing in Meissner lamellar cells. Shown are exemplar action potential traces (left) and quantification of mechanically evoked firing (right) from three Meissner lamellar cells (thin lines). Thick line connects means \pm SEM. (H) The number of action potentials is maximal when MA current is at its peak. Shown is a cumulative frequency distribution of the number of action potentials (circles) evoked by mechanical stimulation of four Meissner lamellar cells to 8- $\mu \mathrm{m}$ depth, fitted to the single exponential equation (line) and plotted against peak-normalized MA current profile.

\section{DISCUSSION}

Here, we used tactile specialist ducks to investigate functional properties of lamellar cells from Meissner and Pacinian corpuscles. The exceptionally high density of corpuscles in duck bill skin and the accessibility of these structures to electrophysiological analysis suggest that this nonstandard model organism could complement rodent models in uncovering basic principles of mechanotransduction in glabrous skin, from the perspective of a tactile specialist. We have shown that Meissner lamellar cells are non-neuronal mechanosensors that can generate $\mathrm{Ca}^{2+}$-dependent action potentials via $\mathrm{R}$-type $\mathrm{Ca}_{\mathrm{v}}$ channels. To our knowledge, this is the only non-neuronal cell type that uses $\mathrm{R}$-type $\mathrm{Ca}_{\mathrm{v}}$ channels for firing. We detected mechanosensitivity, but not excitability, in Pacinian outer core lamellar cells. Nevertheless, because these cells have high input resistance and depolarize at a fast rate of $\sim 2.7 \mathrm{mV} / \mathrm{pA}$, the robust MA current that they produce $(\sim 8.0 \mathrm{pA} / \mu \mathrm{m})$ is sufficient to completely depolarize the membrane in response to a $\sim 2.5-\mu \mathrm{m}$ indentation without the need for amplification via voltage-activated machinery. The MA currents pro- duced by Pacinian and Meissner lamellar cells are different from each other and from MA currents produced by Piezo2, a mechanically gated ion channel with a prominent role in somatosensory mechanotransduction in vertebrates $(19,35-42)$. The decay kinetics of Pacinian MA current is slow $\left(\tau_{\text {decay- } 80 \mathrm{mV}} \sim 48.7 \mathrm{~ms}\right.$ ) and is weakly affected by voltage. In contrast, the decay kinetics of Piezo2 is fast $\left(\tau_{\text {decay }}-80 \mathrm{mV}<10 \mathrm{~ms}\right)$ and becomes significantly slower with depolarization $(35,43)$. The MA current produced by Meissner lamellar cells bears more resemblance to Piezo2: It decays with fast kinetics $\left(\tau_{\text {decay-80 }} \mathrm{mV} \sim 12 \mathrm{~ms}\right)$ and slightly, but significantly, decelerates with depolarization. However, because the rate of Piezo2 decay can be influenced by cellular factors, whether lamellar MA currents reported here are mediated by Piezo2 with modified function (44-46), or by other proteins (47-50), remains to be determined. Our transcriptome analysis of duck bill skin revealed expression of a number of known and putative mechanotransducing ion channels, including Piezo1, Piezo2, transmembrane channel-like protein 2 (TMC2), and transmembrane protein 63 (Tmem63) (fig. S6). 
The identification of active touch detection in lamellar cells within Pacinian and Meissner corpuscles suggests that their function extends beyond passive structural support for the neuronal afferent. That removal of the layers surrounding the afferent ending in Pacinian corpuscles converts neuronal firing from rapidly to slowly adapting has long served as evidence that lamellar cells form a passive mechanical filter that prevent static stimuli from reaching the afferent (13). By inference, a similar role has been attributed to the interdigitating protrusions formed between lamellar cells and the neuron in Meissner corpuscles. Although duck Meissner corpuscles display rapidly adapting firing like their mammalian counterparts and have similar frequency tuning characteristics, their lamellar cells form only minimal interdigitations with the neuron. This suggests that extensive mechanical layers around the neuron may be important but not the only prerequisite for rapid adaptation. We instead propose that lamellar cells play an active role in shaping the rapid adaptation of afferent firing, a process that endows Pacinian and Meissner corpuscles with exquisite sensitivity to transient pressure and vibration.

Both types of corpuscle contain molecular components of synaptic machinery (14-16). Consistently, our electron microscopic analysis revealed the presence of dense core vesicles in duck Meissner lamellar cells. This raises the possibility that mechanically evoked excitation of lamellar cells triggers the release of neuropeptides or other signaling molecules to shape afferent response. This release could either potentiate or inhibit afferent firing, serving as a fine-tuning mechanism for detection and transmission of mechanosensory signals.

\section{MATERIALS AND METHODS \\ Animals}

Experiments with Pekin duck embryos (Anas platyrhynchos domesticus) were approved by and performed in accordance with guidelines of the Institutional Animal Case and Use Committee of Yale University (protocol 2018-11526).

\section{Preparation of duck bill skin}

Pacinian and Meissner corpuscles acquire functionality several days before hatching and become capable of producing a rapidly adapting discharge in the innervating mechanoreceptor in response to touch as early as embryonic day 24 (E24) to E26, similar to corpuscles from adult animals (19-21). A patch of skin ( $5 \mathrm{~mm}$ by $10 \mathrm{~mm})$ from E24 to E26 duck embryo was peeled from the dorsal surface of the upper bill, and the epidermis was mechanically removed to expose Pacinian and Meissner corpuscles. Skin was incubated in collagenase P ( $2 \mathrm{mg} / \mathrm{ml}$; Roche) in Krebs solution $(117 \mathrm{mM} \mathrm{NaCl}$, $3.5 \mathrm{mM} \mathrm{KCl}, 2.5 \mathrm{mM} \mathrm{CaCl}_{2}, 1.2 \mathrm{mM} \mathrm{MgCl}_{2}, 1.2 \mathrm{mM} \mathrm{NaH}_{2} \mathrm{PO}_{4}$, $25 \mathrm{mM} \mathrm{NaHCO}_{3}$, and $11 \mathrm{mM}$ glucose, saturated with $95 \% \mathrm{O}_{2}$ and $5 \% \mathrm{CO}_{2}$ to $\mathrm{pH} 7.3-7.4$ at $22^{\circ} \mathrm{C}$ ) for 20 to $25 \mathrm{~min}$, washed three times with Krebs, and imaged external side up on an Olympus BX51WI upright microscope equipped with an ORCA-Flash 2.8 camera (Hamamatsu).

\section{Patch-clamp electrophysiology of lamellar cells}

Recordings were carried out at room temperature using a MultiClamp 700B amplifier and digitized using a Digidata 1550 (Molecular Devices). Patch pipettes were pulled using a P-1000 puller (Sutter Instruments) from $1.5-\mathrm{mm}$ borosilicate glass with a tip resistance of 1.5 to 3 megohms.
Voltage-clamp recordings were acquired in the whole-cell mode using pCLAMP 10 software, sampled at $20 \mathrm{kHz}$, and low-pass filtered at $10 \mathrm{kHz}$. Voltage-clamp experiments were recorded from a holding potential of $-80 \mathrm{mV}$, using the following solutions: Internal-Cs: $133 \mathrm{mM}$ CsCl, $5 \mathrm{mM}$ EGTA, $1 \mathrm{mM} \mathrm{CaCl}_{2}, 1 \mathrm{mM} \mathrm{MgCl}_{2}, 10 \mathrm{mM}$ Hepes, $4 \mathrm{mM} \mathrm{Mg-ATP} \mathrm{(adenosine} \mathrm{triphosphate),} \mathrm{and} 0.4 \mathrm{Na}_{2}-\mathrm{GTP}$ (guanosine triphosphate; $\mathrm{pH} 7.3$ ) with $\mathrm{CsOH}$; Internal-K: $135 \mathrm{mM}$ K-gluconate, $5 \mathrm{mM} \mathrm{KCl}, 0.5 \mathrm{mM} \mathrm{CaCl}_{2}, 2 \mathrm{mM} \mathrm{MgCl}_{2}, 5 \mathrm{mM}$ EGTA, $5 \mathrm{mM}$ Hepes, $5 \mathrm{mM} \mathrm{Na}{ }_{2} \mathrm{ATP}$, and $0.5 \mathrm{mM}$ GTP-tris ( $\mathrm{pH} 7.3$ ) with $\mathrm{KOH}$; Bath Ringer: $140 \mathrm{mM} \mathrm{NaCl}, 5 \mathrm{mM} \mathrm{KCl}, 10 \mathrm{mM}$ Hepes, $2.5 \mathrm{mM} \mathrm{CaCl}_{2}, 1 \mathrm{mM} \mathrm{MgCl}_{2}$, and $10 \mathrm{mM}$ glucose (pH 7.4) with $\mathrm{NaOH}$. Voltage-gated potassium currents were recorded using Internal-K and Bath Ringer. Currents were elicited by 500 -ms voltage steps from $-100 \mathrm{mV}$, in $10-\mathrm{mV}$ increments. Voltage-gated sodium and calcium $\left(\mathrm{Ca}_{\mathrm{v}}\right)$ currents were recorded using Internal-Cs and Bath Ringer supplemented or not with $300 \mu \mathrm{M} \mathrm{CdCl}_{2}$ or $20 \mu \mathrm{M}$ $\mathrm{CaCl}_{2}$. Currents were elicited using 500 -ms voltage steps from $-100 \mathrm{mV}$, in $10-\mathrm{mV}$ increments. Each voltage step was proceeded by a $500-\mathrm{ms}$ hyperpolarizing step to $-120 \mathrm{mV}$ to remove channel inactivation. Leak current was subtracted using the $\mathrm{P} / 4$ protocol. Series resistance was compensated at $50 \%$. Peak $\mathrm{Ca}_{\mathrm{v}}$ currents were converted to conductance using the equation $G=I /\left(V_{\mathrm{m}}-E_{\mathrm{rev}}\right)$, where $G$ is the conductance, $I$ is the peak $\mathrm{Ca}_{\mathrm{v}}$ current, $V_{\mathrm{m}}$ is the membrane potential, and $E_{\mathrm{rev}}$ is the reversal potential. The conductance data were fit with the modified Boltzmann equation, $G=G_{\min }+\left(G_{\max }-G_{\min }\right) /$ $\left(1+\exp ^{\wedge}\left(\left[V_{1 / 2}-V_{\mathrm{m}}\right] / k\right)\right)$, where $G_{\min }$ and $G_{\max }$ are minimal and maximal conductance, respectively, $V_{\mathrm{m}}$ is the voltage, $V_{1 / 2}$ is the voltage at which the channels reached $50 \%$ of their maximal conductance, and $k$ is the slope of the curve.

MA currents were recorded in Internal-Cs and Bath Ringer at a $-60-\mathrm{mV}$ holding potential. After whole-cell formation, a blunt glass probe (2 to $4 \mu \mathrm{m}$ at the tip) mounted on a piezoelectric-driven actuator (Physik Instrumente $\mathrm{GmbH}$ ) was positioned to touch the corpuscle at the side opposite to the patch pipette. The probe mounted was moved at a velocity of $800 \mu \mathrm{m} / \mathrm{s}$ toward the corpuscle in $1-\mu \mathrm{m}$ increments, held in position for $150 \mathrm{~ms}$ and then retracted at the same velocity.

To visualize lamellar cells, Lucifer yellow was added to internal solution at concentration of $2 \mathrm{mM}$. Resting membrane potentials were measured upon break-in using Internal-K and Bath Ringer. Voltage-clamp experiments and resting membrane potential measurements were corrected offline for liquid junction potential calculated in Clampex 10.7.

Current-clamp experiments were recorded using Internal-K and Krebs in the bath. Recordings were started 2 min after break-in to stabilize the action potential firing. Changes in membrane potential were recorded in response to 1-s current pulses from a 0 - to - 30-pA holding, in 10-pA increments. Current-clamp experiments were not corrected for liquid junction potential. For pharmacological experiments, bath solution was supplemented with the following: $300 \mu \mathrm{M}$ $\mathrm{CdCl}_{2}, 20 \mu \mathrm{M} \mathrm{CaCl}_{2}, 10 \mu \mathrm{M}$ felodipine (Abcam), a mix of $10 \mu \mathrm{M}$ nimodipine and $5 \mu \mathrm{M}$ isradipine (Alomone), $10 \mu \mathrm{M}$ nifedipine (Alomone), agatoxin mix ( $1 \mu \mathrm{M} \omega$-agatoxin IVA and $1 \mu \mathrm{M} \omega$-agatoxin TK from Alomone), conotoxin mix ( $5 \mu \mathrm{M} \omega$-conotoxin CnVIIA, $10 \mathrm{nM}$ $\omega$-conotoxin CVIB, $10 \mathrm{nM} \omega$-conotoxin CVIE, $1 \mu \mathrm{M} \omega$-conotoxin MVIIC, and $1 \mu \mathrm{M} \omega$-conotoxin MVIID from Alomone), $1 \mu \mathrm{M}$ SNX-482 (from Alomone or Peptides International), $5 \mu \mathrm{M}$ mibefradil ${ }^{*} 2 \mathrm{HCl}$, $200 \mathrm{nM}$ kurtoxin (Alomone), and $200 \mu \mathrm{M}$ tetrodotoxin citrate (Tocris). Paired recordings were performed 1 to $10 \mathrm{~min}$ after the 
addition of small-molecule drugs or 1 to 20 min after the addition of peptide toxins. The frequency distribution of mechanically evoked action potentials was obtained by binning the number of action potentials by 9 -ms intervals, followed by fitting the resulting data to the single exponential decay equation $Y=\left(Y_{0}-Y_{\infty}\right) \times \exp ^{\wedge}\left(-t / \tau_{\text {decay }}\right)+Y_{\infty}$, where $t$ is the time from the beginning of current injection, $Y_{0}$ and $Y_{\infty}$ are the percentages of the number of mechanically evoked action potentials at $t=0$ and at infinity, respectively, and $\tau_{\text {decay }}$ is the decay constant.

\section{Preparation of trigeminal neurons}

Trigeminal neurons from embryonic duck (E24 to E26) were acutely dissociated as previously described $(19,26)$. Dissected duck trigeminal ganglia were chopped with scissors in $500 \mu \mathrm{l}$ of ice-cold Hanks' balanced salt solution (HBSS), dissociated by adding $500 \mu$ l of collagenase P ( $2 \mathrm{mg} / \mathrm{ml}$; Roche) dissolved in HBSS, and incubated for $15 \mathrm{~min}$ at $37^{\circ} \mathrm{C}$, followed by incubation in $500 \mu \mathrm{l}$ of $0.25 \%$ trypsin-EDTA for $10 \mathrm{~min}$ at $37^{\circ} \mathrm{C}$. The trypsin was then removed, and the residual trypsin was quenched by adding $750 \mu \mathrm{l}$ of prewarmed DMEM+ medium [Dulbecco's modified Eagle's medium (DMEM) supplemented with $10 \%$ fetal bovine serum, $1 \%$ penicillin-streptomycin, and $2 \mathrm{mM}$ glutamine]. Cells were triturated gently with plastic P1000 and P200 pipettes and collected by centrifugation for $3 \mathrm{~min}$ at $100 \mathrm{~g}$. Cells were resuspended in DMEM+ medium and plated onto the Matrigel (BD Bioscience, Billerica, MA)-precoated coverslips in a 12-well cell culture plate. DMEM+ medium $(0.5 \mathrm{ml})$ was added into each well following incubation at $37^{\circ} \mathrm{C}$ in $5 \% \mathrm{CO}_{2}$ for 30 to $45 \mathrm{~min}$. MA current measurements were performed within 48 hours after plating.

\section{Patch-clamp electrophysiology of trigeminal neurons}

Voltage-clamp recordings were acquired in the whole-cell mode using pCLAMP software using 1.5-mm borosilicate glass with a tip resistance of 1.5 to 5 megohms. Recordings were performed in Bath Ringer, sampled at $20 \mathrm{kHz}$, and low-pass filtered at 2 to $10 \mathrm{kHz}$. Internal solution contained the following: $130 \mathrm{mM} \mathrm{K}$-methanesulfonate, $20 \mathrm{mM} \mathrm{KCl}, 1 \mathrm{mM} \mathrm{MgCl} 2,10 \mathrm{mM}$ Hepes, $3 \mathrm{mM} \mathrm{Na}_{2} \mathrm{ATP}, 0.06 \mathrm{mM}$ $\mathrm{Na}_{2} \mathrm{GTP}$, and $0.2 \mathrm{mM}$ EGTA (pH 7.3) with $\mathrm{KOH}$ (final $\left[\mathrm{K}^{+}\right]=$ $150.5 \mathrm{mM}$ ). Before mechanical stimulation, current was injected in current-clamp mode to elicit neuronal firing to ensure neuronal fitness. Mechanical stimulation was performed using a blunt glass probe positioned at $32^{\circ}$ to $55^{\circ}$ relative to the cell, as described above for corpuscles. Membrane potential was clamped at $-60 \mathrm{mV}$. Neurons with MA current were classified on the basis of the rate of MA current inactivation $\left(\tau_{\text {decay }}\right)$ as fast inactivating $\left(\tau_{\text {decay }}<\right.$ $10 \mathrm{~ms}$ ), intermediately inactivating $\left(\tau_{\text {decay }}=10\right.$ to $30 \mathrm{~ms}$ ), and slow inactivating $\left(\tau_{\text {decay }}>30 \mathrm{~ms}\right.$ ), as previously described (26): The decaying component of MA current was fit to the single exponential decay equation $I=\Delta I \times \exp ^{\wedge}\left(-\mathrm{t} / \tau_{\text {decay }}\right)$, where $\Delta I$ is the difference between peak MA current and baseline, $t$ is the time from the peak current (the start of the fit), and $\tau_{\text {decay }}$ is the decay constant. Resultant $\tau_{\text {decay }}$ for each neuron represent an average from traces with the top $75 \%$ of MA amplitude (35). MA current rise time $\left(\tau_{\text {rise }}\right)$ was quantified by fitting a single exponential function in a similar manner as for $\tau_{\text {decay. }}$

\section{RNA sequencing}

Total RNA was isolated from duck bill skin using the TRIzol reagent (Thermo Fisher Scientific, Waltham, MA) according to the manufacturer's instructions. RNA integrity was assessed on the basis of RNA integrity number (RIN) values obtained with Agilent Bioanalyzer. Library preparation and sequencing were carried out at the Yale Center for Genome Analysis. mRNA was purified from $\sim 200$ ng of total RNA with oligo-dT beads. Strand-specific sequencing libraries were prepared using the KAPA mRNA HyperPrep Kit (Roche Sequencing Solutions, Pleasanton, CA). Libraries were sequenced on Illumina NovaSeq sequencer in the 100-base pair paired-end sequencing mode according to the manufacturer's protocols with multiple samples pooled per lane. A total of $\sim 50$ million to 69 million sequencing read pairs per sample were obtained. The sequencing data were processed on the Yale High Performance Computing cluster. Raw sequencing reads were filtered and trimmed to retain high-quality reads using Trimmomatic v0.36 with default parameters. Filtered high-quality reads from all samples were aligned to duck reference genome using the STAR aligner v2.5.4b with default parameters. The reference genome (A. platyrhynchos, BGI_duck_1.0) and gene annotation (National Center for Biotechnology Information release 102) were obtained from the National Center for Biotechnology Information (accessed on 5 August 2018). The gene annotation was filtered to include only protein-coding genes. Aligned reads were counted by featureCounts program within the Subread package v1.6.2 with default parameters. Raw read counts were processed and converted to "mRNA fragments per kilobase of exon per million mapped fragments" values by edgeR v3.22.3. The RNA sequencing data were deposited to the Gene Expression Omnibus (accession number: GSE155529).

\section{Calcium imaging}

Live-cell ratiometric calcium imaging was performed on duck bill skin patches at room temperature using an Axio Observer $\mathrm{Z1}$ inverted microscope (Zeiss) equipped with an ORCA-Flash 4.0 camera (Hamamatsu) using MetaFluor software (Molecular Devices). After collagenase treatment, skin patch was loaded with $10 \mathrm{mM}$ Fura-2 AM (Thermo Fisher Scientific) and 0.02\% Pluronic F-127 in Ringer solution for $30 \mathrm{~min}$ at room temperature and washed three times with Ringer solution. The skin was then visualized and exposed to a high $-\mathrm{K}^{+}$solution, containing the following: $10 \mathrm{mM} \mathrm{NaCl}$, $135 \mathrm{mM} \mathrm{KCl}, 2 \mathrm{mM} \mathrm{CaCl}$, $2 \mathrm{mM} \mathrm{MgCl}_{2}, 10 \mathrm{mM}$ glucose, and 10 Hepes ( $\mathrm{pH} 7.4$; with $\mathrm{KOH}$ ). Background signal was quantified from skin areas devoid of corpuscles.

\section{Electron microscopy}

Freshly peeled duck bill skin was fixed in Karnovsky fixative at $4^{\circ} \mathrm{C}$ for 1 hour, washed in $0.1 \mathrm{M}$ sodium cacodylate buffer $(\mathrm{pH} 7.4)$, postfixed in $1 \%$ osmium tetroxide for 1 hour in the dark on ice. The tissue was stained in Kellenberger solution for 1 hour at room temperature after washing in distilled water, dehydrated in a series of alcohols and propylene oxide, then embedded in EMbed 812, and polymerized overnight at $60^{\circ} \mathrm{C}$. All solutions were supplied by Electron Microscopy Sciences, Hatfield, PA. Ultrathin sections were obtained on a Leica Ultracut UCT ultramicrotome at $70 \mathrm{~nm}$, stained in $1.5 \%$ aqueous uranyl acetate and Reynolds' lead stains, and imaged on an FEI Tecnai G2 Spirit BioTWIN electron microscope.

\section{Quantification and statistical analysis}

Electrophysiological data from corpuscles and trigeminal neurons were obtained from skin preparations from at least three animals. All measurements were taken from distinct samples. Data were analyzed and plotted using GraphPad Prism 8.4.3 (GraphPad Software 
Inc.) and expressed as means \pm SEM or as individual points. Statistical tests were chosen on the basis of experimental setup, sample size, and normality of distribution, as determined by the KolmogorovSmirnov test, and are specified in the figure legends. Adjustments for multiple comparisons were performed where appropriate.

\section{SUPPLEMENTARY MATERIALS}

Supplementary material for this article is available at http://advances.sciencemag.org/cgi/ content/full/6/51/eabe6393/DC1

View/request a protocol for this paper from Bio-protocol.

\section{REFERENCES AND NOTES}

1. L. L. Orefice, A. L. Zimmerman, A. M. Chirila, S. J. Sleboda, J. P. Head, D. D. Ginty, Peripheral mechanosensory neuron dysfunction underlies tactile and behavioral deficits in mouse models of ASDs. Cell 166, 299-313 (2016).

2. E. R. Schneider, E. O. Gracheva, S. N. Bagriantsev, Evolutionary specialization of tactile perception in vertebrates. Phys. Ther. 31, 193-200 (2016).

3. M. A. Srinivasan, J. M. Whitehouse, R. H. LaMotte, Tactile detection of slip: Surface microgeometry and peripheral neural codes. J. Neurophysiol. 63, 1323-1332 (1990).

4. K. O. Johnson, T. Yoshioka, F. Vega-Bermudez, Tactile functions of mechanoreceptive afferents innervating the hand. J. Clin. Neurophysiol. 17, 539-558 (2000)

5. V. E. Abraira, D. D. Ginty, The sensory neurons of touch. Neuron 79, 618-639 (2013).

6. K. C. Catania, J. H. Kaas, Somatosensory fovea in the star-nosed mole: Behavioral use of the star in relation to innervation patterns and cortical representation. J. Comp. Neurol. 387, 215-233 (1997).

7. K. A. Gerhold, M. Pellegrino, M. Tsunozaki, T. Morita, D. B. Leitch, P. R. Tsuruda, R. B. Brem, K. C. Catania, D. M. Bautista, The star-nosed mole reveals clues to the molecular basis of mammalian touch. PLOS ONE 8, e55001 (2013).

8. P. D. Marasco, K. C. Catania, Response properties of primary afferents supplying Eimer's organ. J. Exp. Biol. 210, 765-780 (2007).

9. M. S. Fleming, W. Luo, The anatomy, function, and development of mammalian $A \beta$ low-threshold mechanoreceptors. Front. Biol. 8, 10.1007/s11515-013-1271-1 (2013).

10. F. Moehring, P. Halder, R. P. Seal, C. L. Stucky, Uncovering the cells and circuits of touch in normal and pathological settings. Neuron 100, 349-360 (2018).

11. N. L. Neubarth, A. J. Emanuel, Y. Liu, M. W. Springel, A. Handler, Q. Zhang, B. P. Lehnert, C. Guo, L. L. Orefice, A. Abdelaziz, M. M. DeLisle, M. Iskols, J. Rhyins, S. J. Kim, S. J. Cattel, W. Regehr, C. D. Harvey, J. Drugowitsch, D. D. Ginty, Meissner corpuscles and their spatially intermingled afferents underlie gentle touch perception. Science $\mathbf{3 6 8}$, eabb2751 (2020).

12. F. Schwaller, V. Bégay, G. García-García, F. J. Taberner, R. Moshourab, B. M. Donald, T. Docter, J. Kühnemund, J. Ojeda-Alonso, R. Paricio-Montesinos, S. G. Lechner, J. F. A. Poulet, J. M. Millan, G. R. Lewin, USH2A is a Meissner corpuscle end-organ protein necessary for vibration sensing in mice and humans. bioRxiv 180919 [Preprint]. 2020. https://doi.org/10.1101/2020.07.01.180919.

13. M. Mendelson, W. R. Loewenstein, Mechanisms of receptor adaptation. Science 144, 554-555 (1964).

14. R. Saxod, in Development of Sensory System, C. M. Bate, Ed. (Springer, 1978), chap. 8, pp. 337-417.

15. R. Cobo, Y. García-Mesa, J. García-Piqueras, J. Feito, J. Martín-Cruces, O. García-Suárez, J. A. Vega, in Somatosensory and Motor Research (IntechOpen, 2020), pp. 1-15.

16. L. Pawson, L. T. Prestia, G. K. Mahoney, B. Guclu, P. J. Cox, A. K. Pack, GABAergic/ glutamatergic-glial/neuronal interaction contributes to rapid adaptation in pacinian corpuscles. J. Neurosci. 29, 2695-2705 (2009).

17. G. A. Zweers, Mechanics of the Feeding of the Mallard (Anas Platyrhynchos, L.; Aves, Anseriformes). Contributions to vertebrate evolution (S Karger Pub, ed. 1, 1977).

18. H. Berkhoudt, The morphology and distribution of cutaneous mechanoreceptors (Herbst and Grandry corpuscles) in bill and tongue of the mallard (Anas platyrhynchos L). Neth J. Zool. 30, 1-34 (1980).

19. E. R. Schneider, E. O. Anderson, M. Mastrotto, J. D. Matson, V. P. Schulz, P. G. Gallagher, R. H. LaMotte, E. O. Gracheva, S. N. Bagriantsev, Molecular basis of tactile specialization in the duck bill. Proc. Natl. Acad. Sci. U.S.A. 114, 13036-13041 (2017).

20. K.-M. Gottschaldt, The physiological basis of tactile sensibility in the beak of geese. J. Comp. Physiol. 95, 29-47 (1974).

21. L. M. Leitner, M. Roumy, Mechanosensitive units in the upper bill and in the tongue of the domestic duck. Pflugers Arch. 346, 141-150 (1974).

22. K. M. Gottschaldt, S. Lausmann, The peripheral morphological basis of tactile sensibility in the beak of geese. Cell Tissue Res. 153, 477-496 (1974).

23. N. Cauna, L. L. Ross, The fine structure of Meissner's touch corpuscles of human fingers. J. Biophys. Biochem. Cytol. 8, 467-482 (1960).
24. W. Luo, H. Enomoto, F. L. Rice, J. Milbrandt, D. D. Ginty, Molecular identification of rapidly adapting mechanoreceptors and their developmental dependence on ret signaling. Neuron 64, 841-856 (2009).

25. E. R. Schneider, E. O. Anderson, V. V. Feketa, M. Mastrotto, Y. A. Nikolaev, E. O. Gracheva, S. N. Bagriantsev, A cross-species analysis reveals a general role for Piezo2 in mechanosensory specialization of trigeminal ganglia from tactile specialist birds. Cell Rep. 26, 1979-1987.e3 (2019).

26. E. R. Schneider, M. Mastrotto, W. J. Laursen, V. P. Schulz, J. B. Goodman, O. H. Funk, P. G. Gallagher, E. O. Gracheva, S. N. Bagriantsev, Neuronal mechanism for acute mechanosensitivity in tactile-foraging waterfowl. Proc. Natl. Acad. Sci. U.S.A. 111 14941-14946 (2014).

27. J. Hao, P. Delmas, Multiple desensitization mechanisms of mechanotransducer channels shape firing of mechanosensory neurons. J. Neurosci. 30, 13384-13395 (2010).

28. B. Coste, M. Crest, P. Delmas, Pharmacological dissection and distribution of NaN/Nav1.9, T-type $\mathrm{Ca}^{2+}$ currents, and mechanically activated cation currents in different populations of DRG neurons. J. Gen. Physiol. 129, 57-77 (2007).

29. F. Rugiero, L. J. Drew, J. N. Wood, Kinetic properties of mechanically activated currents in spinal sensory neurons. J. Physiol. 588, 301-314 (2010).

30. S. G. Lechner, H. Frenzel, R. Wang, G. R. Lewin, Developmental waves of mechanosensitivity acquisition in sensory neuron subtypes during embryonic development. EMBO J. 28, 1479-1491 (2009).

31. W. Zheng, Y. A. Nikolaev, E. O. Gracheva, S. N. Bagriantsev, Piezo2 integrates mechanical and thermal cues in vertebrate mechanoreceptors. Proc. Natl. Acad. Sci. U.S.A. 116, 17547-17555 (2019).

32. J. Hu, G. R. Lewin, Mechanosensitive currents in the neurites of cultured mouse sensory neurones. J. Physiol. 577, 815-828 (2006).

33. G. C. McCarter, J. D. Levine, lonic basis of a mechanotransduction current in adult rat dorsal root ganglion neurons. Mol. Pain 2, 28 (2006).

34. G. C. McCarter, D. B. Reichling, J. D. Levine, Mechanical transduction by rat dorsal root ganglion neurons in vitro. Neurosci. Lett. 273, 179-182 (1999).

35. B. Coste, J. Mathur, M. Schmidt, T. J. Earley, S. Ranade, M. J. Petrus, A. E. Dubin, A. Patapoutian, Piezo1 and Piezo2 are essential components of distinct mechanically activated cation channels. Science 330, 55-60 (2010)

36. M. Szczot, J. Liljencrantz, N. Ghitani, A. Barik, R. Lam, J. H. Thompson, D. Bharucha-Goebel, D. Saade, A. Necaise, S. Donkervoort, A. R. Foley, T. Gordon, L. Case, M. C. Bushnell, C. G. Bönnemann, A. T. Chesler, PIEZO2 mediates injury-induced tactile pain in mice and humans. Sci. Transl. Med. 10, eaat9892 (2018).

37. R. Ikeda, M. Cha, J. Ling, Z. Jia, D. Coyle, J. G. Gu, Merkel cells transduce and encode tactile stimuli to drive A $\beta$-afferent impulses. Cell 157, 664-675 (2014).

38. S. Maksimovic, M. Nakatani, Y. Baba, A. M. Nelson, K. L. Marshall, S. A. Wellnitz, P. Firozi, S.-H. Woo, S. Ranade, A. Patapoutian, E. A. Lumpkin, Epidermal Merkel cells are mechanosensory cells that tune mammalian touch receptors. Nature 509, 617-621 (2014).

39. S. H. Woo, S. Ranade, A. D. Weyer, A. E. Dubin, Y. Baba, Z. Qiu, M. Petrus, T. Miyamoto K. Reddy, E. A. Lumpkin, C. L. Stucky, A. Patapoutian, Piezo2 is required for Merkel-cell mechanotransduction. Nature 509, 622-626 (2014).

40. S. S. Ranade, S. H. Woo, A. E. Dubin, R. A. Moshourab, C. Wetzel, M. Petrus, J. Mathur, V. Bégay, B. Coste, J. Mainquist, A. J. Wilson, A. G. Francisco, K. Reddy, Z. Qiu, J. N. Wood, G. R. Lewin, A. Patapoutian, Piezo2 is the major transducer of mechanical forces for touch sensation in mice. Nature 516, 121-125 (2014)

41. S. H. Woo, V. Lukacs, J. C. de Nooij, D. Zaytseva, C. R. Criddle, A. Francisco, T. M. Jessell, K. A. Wilkinson, A. Patapoutian, Piezo2 is the principal mechanotransduction channel for proprioception. Nat. Neurosci. 18, 1756-1762 (2015).

42. C. Alcaino, K. R. Knutson, A. J. Treichel, G. Yildiz, P. R. Strege, D. R. Linden, J. H. Li, A. B. Leiter, J. H. Szurszewski, G. Farrugia, A. Beyder, A population of gut epithelial enterochromaffin cells is mechanosensitive and requires Piezo2 to convert force into serotonin release. Proc. Natl. Acad. Sci. U.S.A. 115, E7632-E7641 (2018).

43. J. Wu, M. Young, A. H. Lewis, A. N. Martfeld, B. Kalmeta, J. Grandl, Inactivation of mechanically activated Piezo 1 ion channels is determined by the C-terminal extracellular domain and the inner pore helix. Cell Rep. 21, 2357-2366 (2017).

44. M. Szczot, L. A. Pogorzala, H. J. Solinski, L. Young, P. Yee, C. E. le Pichon, A. T. Chesler, M. A. Hoon, Cell-type-specific splicing of Piezo2 regulates mechanotransduction. Cell Rep. 21, 2760-2771 (2017)

45. E. O. Anderson, E. R. Schneider, J. D. Matson, E. O. Gracheva, S. N. Bagriantsev, TMEM150C/Tentonin3 is a regulator of mechano-gated ion channels. Cell Rep. 23, 701-708 (2018).

46. Y. Qi, L. Andolfi, F. Frattini, F. Mayer, M. Lazzarino, J. Hu, Membrane stiffening by STOML3 facilitates mechanosensation in sensory neurons. Nat. Commun. 6, 8512 (2015).

47. L. Beaulieu-Laroche, M. Christin, A. Donoghue, F. Agosti, N. Yousefpour, H. Petitjean, A. Davidova, C. Stanton, U. Khan, C. Dietz, E. Faure, T. Fatima, A. M. Pherson, S. Mouchbahani-Constance, D. G. Bisson, L. Haglund, J. A. Ouellet, L. S. Stone, J. Samson, M.-J. Smith, K. Ask, A. Ribeiro-da-Silva, R. Blunck, K. Poole, E. Bourinet, R. Sharif-Naeini, 
TACAN is an ion channel involved in sensing mechanical pain. Cell 180, 956-967.e17 (2020).

48. S. E. Murthy, A. E. Dubin, T. Whitwam, S. Jojoa-Cruz, S. M. Cahalan, S. A. R. Mousavi, A. B. Ward, A. Patapoutian, OSCA/TMEM63 are an evolutionarily conserved family of mechanically activated ion channels. eLife 7, e41844 (2018).

49. A. Patkunarajah, J. H. Stear, M. Moroni, L. Schroeter, J. Blaszkiewicz, J. L. E. Tearle, C. D. Cox, C. Fürst, O. Sánchez-Carranza, M. d. Á. Ocaña Fernández, R. Fleischer, M. Eravci, C. Weise, B. Martinac, M. Biro, G. R. Lewin, K. Poole, TMEM87a/Elkin1, a component of a novel mechanoelectrical transduction pathway, modulates melanoma adhesion and migration. eLife 9, e53308 (2020).

50. B. Pan, N. Akyuz, X.-P. Liu, Y. Asai, C. Nist-Lund, K. Kurima, B. H. Derfler, B. György, W. Limapichat, S. Walujkar, L. N. Wimalasena, M. Sotomayor, D. P. Corey, J. R. Holt, TMC1 forms the pore of mechanosensory transduction channels in vertebrate inner ear hair cells. Neuron 99, 736-753.e6 (2018).

Acknowledgments: We thank S. Mentone for electron microscopy imaging, R. Dashkin for help with data visualization, and members of the Bagriantsev and Gracheva laboratories for contributions throughout the project. Funding: This study was supported by NSF grant 1923127 and NIH grant 1R01NS097547-01A1 (to S.N.B.) and by NSF grants 1754286 and 2015622 and NIH grant 1R01NS091300-01A1 (to E.O.G.). E.R.S. was supported by a postdoctoral fellowship from the Arnold and Mabel Beckman Foundation. Author contributions: E.O.G. and S.N.B. conceived the project. Y.A.N. and E.O.G. developed the skin preparation. Y.A.N. performed electrophysiological and calcium imaging recordings from corpuscles. V.V.F. performed transcriptomic analysis. E.O.A. performed electrophysiological recordings from trigeminal neurons. E.R.S. performed pilot electrophysiological experiments with duck bill skin. Y.A.N., E.O.G., and S.N.B. wrote the paper. Competing interests: The authors declare that they have no competing interests. Data and material availability: All data needed to evaluate the conclusions in the paper are present in the paper and/or the Supplementary Materials. The RNA sequencing data were deposited to the Gene Expression Omnibus (accession number GSE155529). Additional data related to this paper may be requested from the authors.

Submitted 3 September 2020 Accepted 30 October 2020 Published 16 December 2020 $10.1126 /$ sciadv.abe6393

Citation: Y. A. Nikolaev, V. V. Feketa, E. O. Anderson, E. R. Schneider, E. O. Gracheva, S. N. Bagriantsev, Lamellar cells in Pacinian and Meissner corpuscles are touch sensors. Sci. Adv. 6, eabe6393 (2020). 